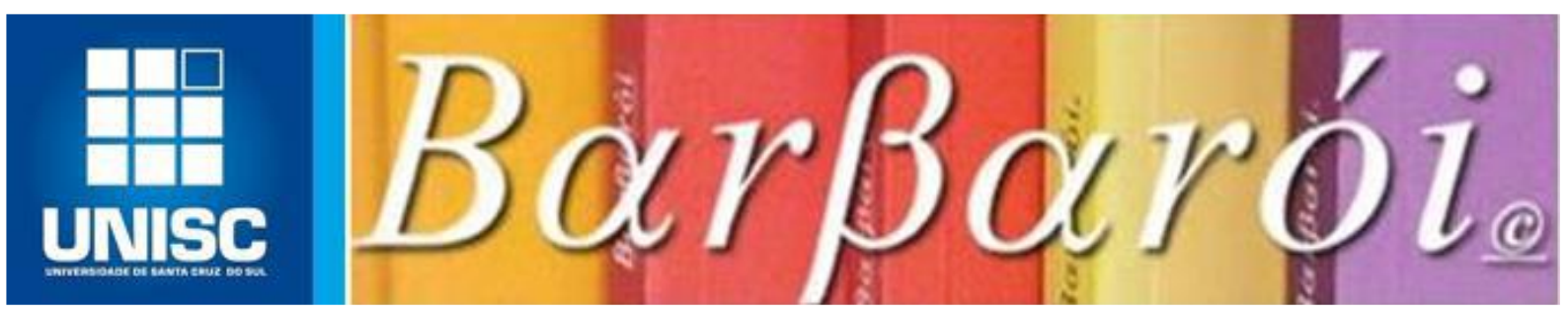

\title{
GLOBALIZAÇÃO, EXCLUSÃO SOCIAL E DIREITOS HUMANOS NA SOCIEDADE CONTEMPORÂNEA: POSSÍVEIS APORTES PARA O DEBATE
}

DOI: http://dx.doi.org/10.17058/barbaroi.v0i57.14472

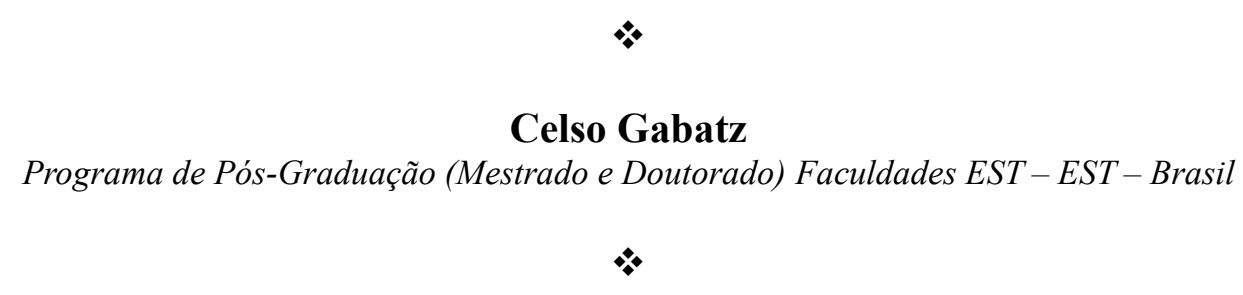

\section{Resumo}

Esta abordagem tem o propósito de esboçar questões conceituais acerca da globalização, exclusão, conflitos sociais e direitos humanos na contemporaneidade. Busca-se discutir os efeitos da globalização nos processos de estruturação, desestruturação e reestruturação dos modelos de interação humana e os possíveis desafios no âmbito das sociabilidades permeadas pelos padrões da sociedade de consumo. A perspectiva esboçada permite compreender que estes processos são o resultado de contínuas transformações e interações engendradas pela ordem econômica capaz de exacerbar valores individuais e coletivos.

Palavras-chave: Globalização; Exclusão; Conflitos; Direitos Humanos.

\section{Introdução}

Como disse, certa vez, o historiador Fernand Braudel (2007), os acontecimentos são como poeira. Eles atravessam a história como breves lampejos; mal nascem e já retornam à noite e, frequentemente, ao esquecimento. O mundo que hoje amplia o conhecimento técnico e científico e as estratégias pautadas para a consolidação do lucro, também se encontra imerso em uma potencial capacidade de destruição da vida. É primordial resgatar as referências que permitam construir caminhos que consolidem a harmonia social e criem soluções por meio do diálogo.

O fenômeno da globalização enseja repercussões nos diferentes âmbitos das relações sociais, contribuindo de forma incisiva para as desigualdades e a precarização das condições de vida dos segmentos, historicamente, excluídos. Nesta perspectiva, os princípios da democracia, cidadania e os direitos humanos, são colocados em questão, principalmente, pela incidência de mecanismos penais. O que se percebe, portanto, é o acentuado desgaste de um Estado em seu 
caráter prestacional em detrimento de um Estado penal capaz de enaltecer o encarceramento dos setores mais vulneráveis da população. A violência e a criminalidade são encaradas como um problema a ser resolvido pelos mecanismos de controle social e pela "mão invisível" do mercado (SMITH, 1996).

Paradoxalmente, e mesmo diante dos enunciados constitucionais respaldados pelas premissas da democracia, o que é possível presenciar na sociedade atual é a permanente violação dos direitos humanos, assim como o recrudescimento da intolerância e a criminalização das diferenças. Os problemas sociais, em geral, não são tratados como problemas que requerem políticas públicas inclusivas, mas, o uso do aparato penal para conter as "desordens" e os conflitos (ROSANVALLON, 1998). O resultado é um estado social mínimo em contraposição a um estado penal máximo. Não por acaso, a complexa realidade conjuntural tende a favorecer o surgimento de movimentos que buscam um passado idealizado para dar sentido à vida no presente. No lugar do convencimento por argumentos racionais ou científicos, reforçam-se os preconceitos, as confusões conceituais, os vazios cognitivos. A ignorância deixa de ser velada para se tornar celebrada (STANLEY, 2018).

A sociedade parece aguardar com ceticismo os desdobramentos de uma perspectiva capaz de reestabelecer um diálogo com as bases que lhe dão sustentação. O cenário é de incertezas, crise, revolta e até indiferença. As análises de conjuntura correm o risco de se mostrarem pouco profícuas dado o aparente dinamismo da realidade vigente. Um dinamismo que, no entanto, nunca deixa de entabular estratégias sombrias e incertas para as classes sociais mais vulneráveis. Assim, o desafio é pensar novos projetos sociais que tenham como fundamento formas e dinâmicas sociais renovadas e renovadoras, que sejam inclusivas e dispostas a remodelar sistemas políticos e sociais em frangalhos (SAFATLE, 2017).

O efetivo exercício dos direitos sob a perspectiva dos direitos humanos demanda ações políticas, jurídicas, emancipatórias, criativas e transformadoras para assegurar aos indivíduos o exercício de sua plena autonomia e dignidade. A transformação das mentalidades é um processo essencial à vivência de direitos. Estes, por sua vez, trazem consigo a prerrogativa de construção de um novo imaginário social sobre os temas dos quais eles tratam (GABATZ, 2017, p. 1-23). Nesta direção, é salutar a participação ativa de pessoas nos diferentes setores da sociedade, inclusive do mundo acadêmico, de modo a contribuir com posicionamentos que apontem para a moderação dos extremismos, fomentando a plena vivência da diversidade como prerrogativa fundante da equidade, da democracia e dos direitos humanos. A intenção, nesta abordagem, a 
partir de uma análise dedutiva é, pois, apresentar questões que auxiliem a compreender e ampliar o horizonte desta incidência.

\section{As Facetas da Globalização}

A globalização não é um fenômeno que se expande de forma única. Trata-se de uma realidade na qual se ampliam os conflitos entre diferentes grupos sociais. Há uma necessidade de um campo hegemônico que é imposto por países com grande poder de ingerência e persuasão. Nem sempre os consensos conseguem ser concretizados na medida em que existem inúmeras divergências no interior deste campo hegemônico.

\footnotetext{
No cabaré da globalização, o estado passa por um strip-tease e no final do espetáculo fica apenas uma necessidade básica: seu poder de repressão. Com sua base material destruída, sua soberania e independência anuladas, sua classe política apagada, a nação-estado torna-se um mero serviço de segurança para as megaempresas (BAUMAN, 1999, p. 74).
}

Cabe destacar, entre outros aspectos, que neste modelo, as economias nacionais são desafiadas para uma transformação de modo a abrir-se ao mercado mundial, dando prioridade para as exportações, a redução dos índices inflacionários e da dívida pública e a diminuição dos valores a serem investidos na proteção social. Há, portanto, uma redução sistemática e estratégica com políticas sociais.

\footnotetext{
Os traços principais desta nova economia mundial são os seguintes: economia dominada pelo sistema financeiro e pelo investimento à escala global; processos de produção flexíveis (...); baixos custos de transporte; revolução nas tecnologias de informação e comunicação; desregulação das economias nacionais; preeminências de agências financeiras multilaterais; emergência de (...) grandes capitalismos transnacionais (SANTOS, 2002, p. 29).
}

São entabuladas e instituídas múltiplas restrições, por vezes drásticas, aos princípios da regulação estatal, de modo a subordinar o Estado às agências internacionais. O fenômeno da globalização tem repercutido significativamente nos mais diferentes espaços das relações humanas, contribuindo de forma efetiva para as desigualdades e a precarização das condições de vida dos segmentos, historicamente, à margem na sociedade.

\footnotetext{
A tendência geral consiste em substituir até ao máximo que for possível o princípio do Estado pelo princípio do mercado e implica pressões por parte de países centrais e das empresas multinacionais sobre os países periféricos e semiperiféricos no sentido de adotarem ou se adequarem às transformações jurídicas e institucionais que estão a ocorrer no centro do sistema mundial (SANTOS, 2002, p. 39).
}

Com o fenômeno da globalização ocorre também uma ocidentalização dos padrões culturais, que passam a permear a vida dos indivíduos a partir de certos costumes e também valores. Dentre eles, pode-se sublinhar esta propensão ao individualismo, uma democracia como modelo político, a racionalidade econômica, os pressupostos do utilitarismo assim como Barbarói, Santa Cruz do Sul, n. 57, p.<29-43>, jul./dez. 2020 
o primado do direito, a publicidade e a ampliação das redes de comunicação virtual. O projeto é a construção de uma cultura global. No entanto, esta intensificação de contatos entre diversas culturas, ao mesmo tempo em que abre caminho para a tolerância e a solidariedade, por outro lado, amplia o surgimento de novas formas de intolerância, xenofobia e preconceitos.

Para a compreensão desta desafiadora realidade social, é preciso, pois, destacar, por extensão, as mudanças ocorridas no tempo e espaço. São essas transformações que o fenômeno da globalização acelera, amplia e difunde.

\begin{abstract}
O sistema mundial em transição é muito complexo porque constituído por três grandes constelações de práticas - práticas interestatais, práticas capitalistas globais e práticas sociais e culturais transnacionais - profundamente entrelaçadas segundo dinâmicas indeterminadas. Trata-se, pois, de um período de grande abertura e indefinição, um período de bifurcação cujas transformações futuras são imperscrutáveis. A própria natureza do sistema mundial em transição é problemática e a ordem possível é a ordem da desordem. Mesmo admitindo que o novo sistema se seguirá ao atual período de transição, não é possível estabelecer uma relação determinada entre a ordem que o sustentará e a ordem caótica do período atual ou a ordem não caótica que a precedeu e que sustentou durante cinco séculos o sistema mundial moderno. Nestas circunstâncias, não admira que o período atual seja objeto de várias e contraditórias leituras (SANTOS, 2002, p 89).
\end{abstract}

Dentro de um contexto global multifacetado, o que se vislumbra é uma realidade alarmante, principalmente, em relação aos níveis de pobreza e a desigualdade social. Há setores marginalizados e excluídos controlados pela lógica do sistema financeiro. De acordo com Sygmunt Bauman (1999, p. 16), para a compreensão da sociedade contemporânea globalizada e neoliberal tão marcada pelo progressivo aumento da exclusão social é imperioso observar as transformações acontecidas em termos de mobilidade do capital. Nesta nova realidade, a distância se transformou em produto a ser alterado pelos meios de transporte, comunicação e transmissão de dados. A distância perdeu um significado efetivo, real. Há uma distinção entre quem "se move" e aqueles "que são movidos". "Alguns podem agora mover-se para fora da localidade quando quiserem. Outros, impotentes, observam a única localidade que habitam movendo-se sobre seus pés" (BAUMAN, 1999, p. 25).

Importa destacar que nesta conjuntura os detentores do poder passam a se manifestar de forma mais abrangente, não necessitando tanto de uma preocupação com aquilo que acontece nos espaços locais. A consequência é um maior isolamento entre os estratos mais ricos em relação aos mais vulneráveis. As camadas mais elitizadas escolhem o isolamento e, inclusive, pagam por esta condição, ao contrário do restante da população que se encontra afastada e, em geral, é incapaz de arcar com o valor cultural, psicológico e até político do seu próprio isolamento.

A globalização pode ser assim definida como a intensificação das relações sociais em escala mundial, que ligam localidades distantes de tal maneira que acontecimentos Barbarói, Santa Cruz do Sul, n. 57, p.<29-43>, jul./dez. 2020 
locais são modelados por eventos ocorrendo a muitas milhas de distância e vice-versa. Este é um processo dialético por que tais acontecimentos locais podem se deslocar numa direção anversa às relações muito distanciadas que os modelam. A transformação local é tanto uma parte da globalização quanto a extensão lateral das conexões sociais através do tempo e do espaço [...]. Ao mesmo tempo em que as relações sociais se tornam lateralmente esticadas e como parte do mesmo processo, vemos o fortalecimento de pressões para autonomia local e identidade cultural regional (GIDDENS, 1991, p. 76-77).

O que se observa é a diluição do espaço público e uma espécie de esfacelamento das interações no meio urbano com a segregação dos diferentes grupos sociais. A esfera pública passa a ser também um ambiente de maior incidência das massas abastadas que não necessitam estar tão ligadas aos aparatos de sociabilidade local. Assim, o espaço público, nas relações da sociedade atual, vai sendo limitando, cada vez mais, e, em decorrência, acontece uma maior incompatibilidade nas discussões, como, por exemplo, nas normas que regulam a convivência e nos valores que poucas vezes são confrontados ou negociados por meio de acordos com os diversos integrantes do tecido social. Uma expressiva parte das decisões, independente do tema, acaba sendo disposta de cima para baixo.

Todo este ambiente também acaba sendo fortemente manipulado pela mídia, cujo objetivo é criar uma constante sensação de perigo. Objetiva-se, assim, fazer com que as pessoas sejam entusiastas das prisões e de condenações com penas maiores. Trata-se de uma premissa que incide sobre uma lógica do caos que precisa ser debelado (WACQUANT, 2001). Há, por óbvio, uma seletividade desta política de "lei e ordem", pois as ações mais prováveis de serem cometidas estão diretamente ligadas com as pessoas para as quais não há lugar nesta pretensa ordem.

No mundo das finanças globais, os governos detêm pouco mais que o papel de distritos policiais superdimensionados; a quantidade e qualidade dos policiais em serviço, varrendo os mendigos, perturbadores e ladrões das ruas, e a firmeza dos muros das prisões assomam entre os principais fatores de 'confiança dos investidores' e, portanto, entre os dados principais considerados quando são tomadas decisões de investir ou de retirar um investimento (BAUMAN, 1999, p.127).

A violência e a criminalidade são encaradas como um problema a ser resolvido pelo sistema penal e pela "mão invisível” do mercado. Para a solução dos complexos desajustes sociais da sociedade, lança-se mão do mercado ou do aprisionamento como as únicas possibilidades de "salvação". De garantia para a segurança e a paz social. Algo que é cada vez mais exigido, principalmente pelas classes dominantes. 


\section{Exclusão e Conflitos Sociais}

Na dimensão humana, a exclusão tem a ver com a busca pela sobrevivência. O acúmulo das experiências de fragilização, precarização e rupturas conduzem os indivíduos para uma condição de alguém 'sem lugar no mundo', com vínculos frágeis ou efêmeros que não constituem uma unidade social de pertencimento. Trata-se de pessoas desvinculadas num sentido material e afetivo e marginalizadas no nível simbólico.

A exclusão se caracteriza não só pela extrema privação material, mas, principalmente, porque essa mesma privação material 'desqualifica' seu portador, no sentido de que lhe retira a qualidade de cidadão, (...), de sujeito e de ser humano, de portador de desejos, vontades e interesses legítimos que o identificam e diferenciam. A exclusão social significa, então, o não encontrar nenhum lugar social, o não pertencimento (...), uma existência limitada à sobrevivência singular e diária (ESCOREL, 1999, p.81).

A exclusão e os conflitos são, ao mesmo tempo, parte de um estado de coisas que foi se sedimentando e de um processo construído ao longo do tempo. Trata-se de um estado de uma realidade que aponta para uma condição alcançada por meio das sucessivas rupturas, como desdobramentos e uma trajetória marcada por múltiplas vulnerabilidades. Por outro lado, a exclusão social é também um processo de condicionamentos sofridos nas diversas dimensões da existência humana que se entrelaçam e acabam agindo umas sobre as outras.

De acordo com o sociólogo francês, Robert Castel (1998), vive-se na contemporaneidade uma fragilidade dos vínculos sociais, a incerteza dos seus estatutos e uma ausência de um "lugar social" para uma parte das pessoas. Trata-se de uma "presença, aparentemente cada vez mais insistente, de indivíduos colocados em situação de flutuação na estrutura social e que povoam seus interstícios sem encontrar um lugar designado" (p.23). Para o autor existiriam “zonas” que vão da integração à desfiliação, constituídas em referência ao mercado de trabalho e as redes de sociabilidade primária. Trata-se de uma relação caracterizada pela premissa do trabalho estável e por uma inserção relacional mais sólida. Mesmo assim, este espaço também estaria envolvido por uma zona intermediária de vulnerabilidade social capaz de combinar a precariedade do trabalho e fragilidade dos suportes de proximidade.

Como referência extrema e também negativa neste processo, estaria a desfiliação, marcada pela ausência de participação em qualquer atividade produtiva. De acordo com esta compreensão, as pessoas estariam marcadas pelos valores utilitaristas do mundo industrial. Existiria uma desqualificação destas no mundo cívico e político quando não inseridas de forma efetiva nesta realidade (SCHWARTZMAN, 2004). Ao não fazer parte da lógica do mercado, elas se transformariam em "forças não sociais" na medida em que não teriam poder de 
influência sobre os rumos da sociedade. Elas não teriam, inclusive, existência social, ou seja, não encontram um lugar reconhecido para a expressão de sua identidade na sociedade.

As múltiplas formas de exclusão representam, sobretudo, a ruptura dos laços sociais estabelecidos. No caso de desemprego e de pobreza, significam a ruptura dos laços econômicos; no caso de exclusões de instituições normativas, a ruptura dos laços institucionais. Podem significar ainda a ruptura dos laços simbólicos. Aqueles delimitados por alguma adesão capaz de vincular atores sociais aos valores da sociedade à qual o indivíduo pertence. Os rompimentos, em geral, precedem a ruptura de algum sentido ou ideal de significação coletiva. Exemplos são alguns dos fenômenos conhecidos nos dias atuais como o caso do terrorismo, os fundamentalismos e as questões correlatas ao racismo (XIBERRAS, 1996).

É primordial ao refletir acerca da exclusão e dos conflitos sociais, considerar a hipótese de que quando a densidade social aumenta, as forças das representações e dos valores comuns tendem a decrescer. A consequência é o surgimento de certas patologias modernas tais como os vícios e a criminalidade. Por sua vez, para o conjunto destes indivíduos o que acontece não é apenas o fenômeno do desvio, da anomia ou da marginalidade provocando a desagregação social, mas, uma recomposição do tecido social com um maior potencial de solidariedade e afinidade nos próprios grupos excluídos, tanto nas populações mais vulneráveis como também nos segmentos formados por gostos, vícios ou então, por exemplo, comunidades sexuais e étnicas (DOUGLAS; ISHERWOOD, 2005).

Neste cenário, o desafio é que os indivíduos vivam de acordo com as normas delineadas pelos "padrões de normalidade". Quem não consegue adaptar-se aos padrões estabelecidos, inevitavelmente, haverá de ser confinado em alguma prisão de modo a não perturbar a "normalidade" em um ideal de "cidade perfeita". Por definição, haverá também uma rejeição a sua conduta pregressa. $\mathrm{O}$ resultado deste modelo de sociedade, em geral, suscita e engendra a intolerância face à diferença e a exigência do isolamento numa preocupação com a "lei e a ordem", que segrega e exclui os "fora da lei": negros, pobres, mulheres e minorias étnicas e sexuais.

\footnotetext{
A garantia de segurança tende a se configurar na ausência de vizinhos com pensamentos, atitudes e aparência diferentes. A uniformidade alimenta a conformidade e a outra face da conformidade é a intolerância. Numa localidade homogênea é extremamente difícil adquirir as qualidades de caráter e habilidades necessárias para lidar com a diferença humana e situações de incerteza; e na ausência dessas habilidades e qualidades é facílimo temer o outro, simplesmente por ser outro (BAUMAN, 1999, p. 55).
}

O medo e a insegurança, nos dias atuais, não são compreendidos como um problema coletivo, mas, individual. Exemplos para isso são as construções em bairros fechados e 
vigiados, dos espaços públicos com ampla proteção para afastar os indivíduos indesejados ou "perigosos", tornando-se uma estratégia de segregação, sobretudo, nos espaços urbanos. Assim, a forma mais clara de inclusão é aquela que acontece por meio do próprio consumo. Com uma divisão entre elite e povo, rico e pobre, advinda dos efeitos da globalização e do neoliberalismo, constata-se uma grande desestruturação das relações sociais no âmbito da sociedade.

Uma das soluções para esta realidade são os instrumentos de controle social colocados em prática por meio do sistema penal, criminalizando e excluindo os mais pobres. Para a liberdade da elite, torna-se imperativo a supressão da liberdade dos pobres e excluídos. Uma supressão da liberdade por meio do confinamento, do encarceramento com variados graus de severidade e rigor. Na sociedade disciplinar teorizada por (FOUCAULT, 1987) o controle social expressava-se através do disciplinamento, cujo propósito era a recuperação moral para o retorno ao convívio na sociedade, combater a preguiça, a indiferença pelas normas sociais.

\begin{abstract}
Nas atuais circunstâncias, o confinamento é antes uma alternativa ao emprego, uma maneira de utilizar ou neutralizar uma parcela considerável da população que não é necessária à produção e para qual não há trabalho ao qual se reintegrar (...). A prisão tem hoje a função de exclusão de pessoas habituadas a sua condição de excluídas. A marca dos excluídos na era da compreensão espaço temporal é a imobilidade (...). A questão é tanto mais preocupante do ponto de vista ético pelo fato de que aqueles que punimos são em larga medida pessoas pobres e (...) estigmatizadas que precisam mais de assistência do que punição (BAUMAN, 1999, p. 123).
\end{abstract}

No mundo atual há um aumento considerável do número de pessoas em prisões. Por sua vez, os gastos com o aparato policial e com as "forças de lei e ordem", por extensão, também crescem. Isso mostra que setores da população acabam sendo mais visados por, supostamente, ameaçarem uma ordem social instituída. $\mathrm{O}$ encarceramento de setores marginalizados tem sido usado como instrumento de controle social disposto a neutralizar ou acalmar a ansiedade pública, provocada pela ameaça de setores “desviados” da população.

Outra questão relevante diz respeito ao crescimento, progressivo, das infrações tipificadas como crime e, portanto, suscetíveis ao regime prisional. Isso sem falar no aumento das penas dos crimes tidos como hediondos. Nestes, a regra geral tem a ver com o cumprimento integral em regime fechado em "presídios de segurança máxima”. Há ainda as políticas de "tolerância zero" e as estratégias de segurança máxima com o propósito de consolidar a popularidade dos governos na medida em que se mostra uma capacidade de equacionar os anseios por segurança por parte da população. 


\section{Os Desafios dos Direitos Humanos na Contemporaneidade}

O poder econômico desigual e assimétrico tem determinado, em grande medida, os rumos da sociedade atual. As diferentes organizações adaptadas ao ambiente social gerado pela globalização criam e recriam valores e visões de mundo e podem, tanto ameaçar a vida humana, a democracia e a participação das pessoas e grupos, como também, protegê-los. No entanto, não se pode esquecer que as redes que visam defender a vida e os valores humanos estão em enorme desproporção de poder se comparada com as grandes corporações econômicas.

Os filósofos políticos Michael Hardt e Antonio Negri (2001) mostram, no livro "Império", que a realidade social e política do mundo globalizado são orientadas por uma forma de organização diferente da antiga hierarquia vertical, com um rei ou país no topo exercendo o poder sobre os demais. Ou também diferente das estruturas de poder que se configuravam como numa árvore (partindo de um tronco único para diversas ramificações ou galhos cada vez menores). A nova forma de dominação, denominada de "Império" é constituída por redes assimétricas. Um lado com mais poder do que o outro. Um poder desigual e desproporcional. Dessa forma, as relações de poder e de dominação se dão mais pela perspectiva cultural e econômica do que pelo uso da força, como no passado.

Entidades organizadas como as como corporações empresariais, organizações não governamentais e até mesmo grupos terroristas, têm mais poder e mobilidade nos dias de hoje e podem influenciar decisivamente, tanto para o bem, como para o mal. A sociedade vai consolidando valores e visões de mundo. O Estado, os partidos políticos, as empresas tradicionais ou familiares que valorizam a produção em menor escala tornam os espaços de interação um lugar para um menor poder e influência.

Este Império global é o Império do capitalismo financeiro, o eixo econômico que congrega, com seu poder virtual, os outros poderes: político, militar, cultural. Toda a diversidade do mundo reduz-se a uma única maneira lícita - para o Império - de gerir o econômico. A verdadeira rede que contém o Império é a rede financeira internacional: a isso devem submeter-se povos e expectativas, culturas e nações (MIGUEZ; RIEGER; MO SUNG, 2012, p. 29).

Para o seu pleno domínio os grupos hegemônicos que detêm o poder e que, em boa parte das vezes estão invisíveis, desenvolvem-se práticas articulando as ações a partir de certos símbolos, subjetividades e forças midiáticas que geram uma cosmovisão e uma forma estratégica de gerir a vida e a sociedade. A partir desta realidade são criadas condições para a negação ou mesmo a anulação de outros poderes, como aqueles ligados a grupos subalternos, mulheres, jovens, entre outros. Também se bloqueia o surgimento de opções políticas 
alternativas à dominação. Além disso, dentro do espírito do Império não há lugar para dissensos, alteridades ou antagonismos (DEMO, 2003).

São grupos que se sentem no direito de regular e reger a natureza humana. Também buscam camuflar a sua violência com um discurso artificial de igualdade, de paz e de desenvolvimento, sem levar em conta os meandros da justiça ou da equidade. Os processos contra hegemônicos a partir desta situação são, em geral, difíceis de serem descritos, justamente por serem diversos e, por vezes, localizados em diferentes regiões e nem sempre com estruturas centralizadas de articulação. No entanto, na dimensão dos direitos humanos eles podem ser reconhecidos por ser um espaço de questionamento através de ideias e práticas sociais que visam identificar os processos de exclusão, sobretudo das esferas da produção presentes na dinâmica da globalização econômica e um espaço para propor alternativas para a sociedade (MARTINS, 2002).

As lutas contra as hegemonias e pelos direitos humanos almejam as mudanças nas estruturas sociais que são responsáveis pela sistemática do sofrimento das pessoas. São lutas materiais que devem se dirigir à economia subjacente à produção e à reprodução de relações sociais desiguais, mesmo quando estas estão menos ligadas à exploração capitalista e a uma hierarquia de base classista, como no caso das relações identitárias onde se vislumbram estigmas de discriminação sexual, racial, étnica, religiosa. São também lutas materiais que repercutem recursos políticos, financeiros e humanos para construir organizações e gerar militância (SANTOS, 2013, p.134).

Outra questão importante acerca da realidade contemporânea em sua relação com os direitos humanos tem a ver com a articulação de grupos "conservadores" que embasam as suas ações sublinhadas pelo entendimento de que a modernidade fez emergir a decadência moral, social, cultural e política. Uma decadência que estaria diretamente ligada a um "liberalismo teológico" dos movimentos de esquerda, a suposta subversão promovida pelo feminismo, o crescimento da "libertinagem sexual", a ameaça das fações políticas "comunistas", o afrouxamento das autoridades, das leis, punição aos infratores e o aumento da criminalidade (GABATZ, 2017, p. 4-7).

É preciso salientar que a reconfiguração da democracia nas últimas décadas produziu avanços e gerou modificações importantes nas estruturas políticas. Houve mobilização e abertura para que surgissem novos agentes. Neste contexto, foram sendo demarcados fluxos, instaurados intercâmbios e ampliados domínios. Foram surgindo novas vozes que estenderam a repercussão de temas concernentes à diversidade de gênero, sexual, cultural, étnica e, também, 
souberam repercutir as demandas pela garantia de políticas de convivência e alteridade, consolidação de direitos e tolerância (CARVALHO, 2008).

Desta maneira, o que ocorre é uma permanente e obstinada busca por influir no espaço público visando consolidar determinadas leis, subjugar políticas públicas de inclusão das minorias, criticar materiais educacionais produzidos pelo Estado e ampliar o horizonte dos direitos constitucionais. É inegável que os traços de uma sociedade que não concentra os seus esforços para construir meios para que a equidade e o entendimento prevaleçam sempre estará sujeita ao autoritarismo, narcisismo, opressão, medo, degradação econômica e social, pouco espírito reflexivo, falta de autonomia, competição exacerbada, inclinação para compreender a técnica como um fim em si mesmo, incapacidade para amar, dialogar e partilhar (BECK, 1999).

Convém observar também que as intensas transformações sociais, vividas nas últimas décadas, desafiam os esquemas clássicos de representatividade. A atual temporalidade acelerada por um imediatismo tecnológico e midiático tende a entrar em confronto com o tempo político, o tempo representativo, muito mais demorado. Passamos da "democracia dos partidos" para uma "democracia das audiências" (MANIN, 1997), com a substituição do espaço público de debate pelo protagonismo dos meios de comunicação e com um eleitorado mais fluido, menos fidelizado, que se mobiliza muito mais por certas causas do que por referências partidárias.

O pressuposto, de acordo com o filósofo húngaro, Peter Pál Pelbart, (2003, p. 13) é que "a defesa da vida se tornou lugar comum na contemporaneidade". Para o autor, vive-se um paradoxo em nossos dias: a centralidade e, ao mesmo tempo, a banalidade da vida humana. Esta premissa encontra-se ligada de forma profunda com o desenvolvimento das ciências médicas, da obsessão por aperfeiçoar e modificar os corpos e das inúmeras possibilidades de recodificar os genes, alterar o sexo, artificializar e prolongar a vida de modo a ampliar o espectro da realização pessoal.

Trata-se de um discurso e de um enfrentamento difícil de ser interpretado, porque é, ao mesmo tempo, conservador e progressista, social e individualista. Ele supõe a destruição de um sistema político fragilizado. É uma forma que avança por conta da deterioração da frágil democracia. Ele nasce do sentimento de negação da realidade (MAFFESOLI, 2007). É a ideia de que a política não serve como instrumento de melhoria das condições de vida e que, portanto, é preciso substitui-la como espaço de decisão sem a possibilidade do voto de cada indivíduo. Esta premissa autoritária vai se fortalecendo não apenas nos discursos de quem o defende, mas 
fundamentalmente, no silêncio, na incompreensão e na indiferença de quem, por óbvio, deveria exercitar a sua cidadania.

Para diluir o perigo social representado por contingentes que se deixam manipular por determinados atores ao seguir certos dogmas ou crenças em desencontro com valores democráticos e com respeito à igualdade, é preciso que a educação avance no cumprimento de seu papel de preparar os indivíduos para a cidadania, inclusive no que diz respeito ao desenvolvimento de sua capacidade crítica na promoção da cultura da paz em uma sociedade que almeja valores da justiça social, da igualdade entre os sexos, da eliminação do racismo, sem intolerância religiosa, respeito às minorias, educação universal, equilíbrio e liberdade política.

\section{Conclusão}

A partir da contribuição de diferentes autores, buscou-se compreender que a concepção atual acerca da globalização, exclusão social e direitos humanos, se insere em um cenário desafiador preconizado por forças econômicas, políticas, culturais, provenientes do funcionamento do capitalismo tardio, que convergem, sem a consideração de fronteiras ou de limites, para um domínio na sociedade exercido por elites do poder econômico. Considerou-se a importância da crítica às relações de dominação e de exclusão socioeconômica que marcam a atualidade e que caracterizam o domínio de um "novo Império", capitaneado pelo sistema capitalista, que, mesmo com reações contrárias, condiciona e dirige formas de pensar e agir em diferentes grupos e culturas e os sistemas de valores presentes na sociedade.

O que foi possível descortinar, nesta abordagem, é que com a inadaptação dos antigos métodos de gestão social, explicitadas nas sucessivas crises nos princípios fundamentais de organização e solidariedade, além da própria concepção de direitos, ocorreu uma crise de natureza ideológica sobre a eficácia do Estado em administrar os problemas sociais em função de sua organização, por vezes, distante da realidade vivenciada pelos indivíduos. Há uma inegável dificuldade política, ideológica e econômica, em atuar como agente de proteção social. A consequência é a escalada do medo, da violência, a precarização das condições e relações de trabalho, o aumento do desemprego, entre outros aspectos. O que se constata diante deste quadro é a reconfiguração do espaço público, a desintegração das comunidades urbanas, a separação e a segregação das classes sociais, a extraterritorialidade de uma elite formada por empresários, políticos, magistrados e a totalidade forçada do restante da população.

O espaço público é restrito para que as normas sejam debatidas, para que os valores sejam confrontados e negociados. Há uma falta de clareza entre o que cabe ao privado e o que 
tem a ver com o público. O resultado é que as coisas "venham de cima". Sobram poucas possibilidades de negociação, de diálogo e de consolidação do bem comum. Há uma separação entre os que se movem e os que são movidos. Diante disso, é preciso que os indivíduos hajam dentro de supostos "padrões de normalidade". Quem não consegue adaptar-se aos padrões estabelecidos deve ser confinado de modo a não perturbar aquilo que é tido como normalidade. Esta cidade perfeita, ideal, rejeita a história, a bagagem cultural, as diferenças, a tolerância e a alteridade. Trata-se de uma paranoica preocupação com a lei, a ordem e certos valores. Numa pretensa homogeneidade é extremamente difícil adquirir as habilidades necessárias para lidar com a diferença humana em situações de incerteza; e na ausência dessas habilidades é fácil ter medo ou ódio do outro, simplesmente por ele ser outro.

\title{
GLOBALIZATION, SOCIAL EXCLUSION AND HUMAN RIGHTS IN THE CONTEMPORARY SOCIETY: POSSIBLE CONTRIBUITIONS FOR DISCUSSION
}

\begin{abstract}
This approach aims to outline conceptual questions about globalization, exclusion, social conflicts and human rights in contemporary times. It seeks to discuss the effects of globalization on the processes of structuring, interruption and restructuring of human interaction models and the possible challenges within the scope of sociability permeated by the standards of the consumer society. The outlined perspective allows us to understand that these processes are the result of continuous transformations and interactions generated by the economic order capable of exacerbating individual and collective values.
\end{abstract}

Keywords: Globalization; Exclusion; Conflicts; Human rights.

\section{REFERÊNCIAS}

BAUMAN, Zygmunt. Globalização: as consequências humanas. Rio de Janeiro: Jorge Zahar, 1999.

BECK, Ulrich. O que é Globalização. Equívocos do Globalismo, respostas à Globalização. São Paulo: Paz e Terra, 1999.

BRAUDEL, Fernand. História e Ciências Sociais: a longa duração. In: Escritos sobre a História. São Paulo: Perspectiva, 2007, p. 41-47.

CASTEL, Robert. As metamorfoses da questão social: uma crônica do salário. Petrópolis: Vozes, 1998.

CARVALHO, José Murilo de. Cidadania no Brasil: o longo caminho. Rio de Janeiro: Civilização Brasileira, 2008.

DEMO, Pedro. Pobreza da pobreza. Petrópolis: Vozes, 2003.

DOUGLAS, Mary; ISHERWOOD, Baron. O mundo dos bens: para uma antropologia do consumo. Rio de Janeiro: UFRJ, 2005. 
ESCOREL, Sarah. Vidas ao léu: trajetórias de exclusão social. Rio de Janeiro: Fiocruz, 1999.

FOUCAULT, Michel. Vigiar e punir: nascimento da prisão. Petrópolis: Vozes, 1987.

GABATZ, Celso. Religião, laicidade e direitos sexuais e reprodutivos: a presença de grupos religiosos conservadores nos espaços públicos da contemporaneidade. Revista Estudos de Religião, v. 31, n. 1, UMESP: São Paulo, 2017, p. 01-23.

GIDDENS, Anthony. As Consequências da Modernidade. São Paulo: UNESP, 1991.

HARDT, Michael; NEGRI, Antonio. Império. Rio de Janeiro: Record, 2001.

MAFFESOLI, Michel. O Ritmo da Vida: Variações sobre o Imaginário Pós-Moderno. Rio de Janeiro: Record, 2007.

MANIN, Bernard. The principles of representative government. Cambridge: Cambridge University Press, 1997.

MARTINS, José de Souza. A sociedade vista do abismo: novos estudos sobre exclusão, pobreza e classes sociais. Petrópolis: Vozes, 2002.

MIGUEZ, Néstor; RIEGER, Jörg.; MO SUNG, Jung. Para além do espírito do Império: novas perspectivas em política e religião. São Paulo: Paulinas, 2012.

PELBART, Peter Pál. Vida Capital: Ensaios de biopolítica. São Paulo: Iluminuras, 2003.

ROSANVALLON, Pierre. A nova questão social: repensando o Estado Providência. Brasília: Instituto Teotônio Vilela, 1998.

SAFATLE, Vladimir. Só mais um Esforço. São Paulo: Três Estrelas, 2017.

SANTOS, Boaventura de Souza. Os processos de globalização. In: SANTOS, Boaventura de Souza. A globalização e as ciências sociais. São Paulo: Cortez, 2002.

São Paulo: Cortez, 2013.

Se Deus Fosse um Ativista dos Direitos Humanos.

SCHWARTZMAN, Simon. Pobreza, exclusão social e modernidade: uma introdução ao mundo contemporâneo. São Paulo: Augurium, 2004.

SMITH, Adam. A Riqueza das Nações. São Paulo: Nova Cultural, 1996.

STANLEY, Jason. Como Funciona o Fascismo. A política do "nós" contra "eles". Porto Alegre: L\&PM, 2018.

XIBERRAS, Martine. As teorias da exclusão. Para uma construção do imaginário do desvio. Lisboa: Instituto Piaget, 1996.

WACQUANT, Loic. As prisões da miséria. Rio de Janeiro: Jorge Zahar Editor, 2001. 
Data de recebimento: $05 / 11 / 2019$

Data de aceite: 10/09/2020

\section{Sobre o autor:}

Celso Gabatz é Graduado em Teologia - Faculdades EST (São Leopoldo, RS), Graduado em Sociologia - UNIJUI (Ijuí, RS), Graduado em Filosofia - CEUCLAR (São Paulo, SP), PósGraduado em Ciência da Religião e Docência no Ensino Superior, Mestre em História - UPF (Passo Fundo, RS), Doutor em Ciências Sociais - UNISINOS (São Leopoldo, RS) e PósDoutorando (PNPD-CAPES) Faculdades EST, São Leopoldo-RS. Endereço Eletrônico: gabatz12@hotmail.com 